\title{
Comparative Evaluation of Bond Strength between Ridge Lap Surface of Acrylic Teeth and Denture Base Resin: An In Vitro Study
}

\author{
Eeshita Sharma ${ }^{1}$ Manjit Kumar ${ }^{1} \quad$ Rohit Sharma $^{2} \quad$ Ajay Bansal $^{1} \quad$ Sumit Katoch ${ }^{1}$ \\ 1Department of Prosthodontics, Bhojia Dental College and Hospital, \\ Baddi, Himachal Pradesh, India \\ 2Department of Periodontics, Himachal Dental College, \\ Address for correspondence Manjit Kumar, MDS, Department of \\ Prosthodontics, Bhojia Dental College and Hospital, Baddi, Solan \\ 173205, Himachal Pradesh, India (e-mail: manjitkiran@yahoo.co.in).
}

Sundernagar, Mandi, Himachal Pradesh, India

Dent J Adv Stud 2019;7:12-18

\author{
Abstract \\ Keywords \\ - bond strength \\ - polymethylmethac- \\ rylate \\ - ridge lap surface \\ - monomer \\ - dichloromethane \\ - aluminum oxide \\ abrasive stone
}

Statement of Problem Acrylic teeth are preferred to porcelain teeth in dentures as they unite chemically with denture base resin, but their fracture from denture is common.

Purpose The purpose of this study was to improve the bond strength of denture teeth to acrylic resin denture base by chemical or mechanical modification of the ridge lap surface of denture teeth.

Materials and Methods Total 100 artificial cross-linked acrylic resin central incisors were divided into five groups: group A, 20 samples without modification (control group); group B, 20 samples (ridge lap surface of teeth treated with monomer); group C, 20 samples (ridge lap surface of teeth treated with monomer and the glaze layer removed with aluminum oxide abrasive stone); group D, 20 samples (ridge lap surface of teeth treated with dichloromethane); and group E, 20 samples (dichloromethane application followed by abrasion with aluminum oxide stone on ridge lap surface of teeth). They were mounted on wax blocks, and the blocks were acrylized. The bond strength values were obtained by subjecting the samples to shear compressive load under universal testing machine.

Result The results were subjected to statistical analysis by applying analysis of variance and Bonferroni test for multiple group comparisons, and graphs were plotted. The mean value of bond strength was highest for group $E$ (modified by aluminum oxide abrasion prior to dichloromethane application), followed by group C (modified by aluminum oxide abrasion prior to monomer application), group D (modified by dichloromethane application), group B (modified by monomer application), and lastly group A (control group). Significantly improved bond strength values were obtained in modified groups as compared with the control group.

Conclusion Dichloromethane application followed by aluminum oxide abrasion provided the highest bond strength and is recommended to prevent debonding of the teeth from the denture base.

\section{Introduction}

Routinely denture base material for dental prosthesis used is heat-cured poly methyl methacrylate because of its properties such as better esthetics, low solubility, less toxicity, easy to repair, and simple and economical procedure of fabrication. Since 1940 the polymethylmethacrylate artificial teeth have become popular to be used in artificial dental prosthesis. Bonding of acrylic teeth to denture base material is chemical. Major post-insertion

\section{received}

December 28, 2018

accepted after revision

January 10, 2019

published online

March 28, 2019
DOI https://doi.org/

$10.1055 / \mathrm{s}-0039-1684881$

ISSN 2321-1482.
(C2019 Bhojia Dental College and Hospital affiliated to Himachal Pradesh University
License terms

(우 (1) $\ominus \circledast$ 
complication of artificial prosthesis is debonding of these teeth from denture base material. This debonding of teeth is more problematic in implant-supported overdentures. This debonding is attributed to the direction of concentration of forces. Several studies have been conducted to study and evaluate the bonding of the teeth with denture base materials. The surface that attaches with denture base materials is modified by use of various chemicals, but their results are variable. Nowadays non-polymerized chemicals such as dichloromethane, chloroform, and some adhesive bonding agents are used to increase bond strength between acrylic teeth and denture base materials.

Teeth are the best measure of individuality of a person. Acrylic teeth attached with denture base should demonstrate optimum physical and mechanical properties to withstand rigorous demands of masticatory functions such as chewing, biting, shearing of food, and simultaneously superior esthetics, particularly in the anterior region of the mouth. Mostly cross-linked and polymethyl methacrylate teeth are used for fabrication of artificial prosthesis. The debonding of polymethylmethacrylate teeth from a maxillary denture is not uncommon, especially the teeth in the anterior region. Over the years, many researchers have attempted to increase bonding of the teeth to denture base, either by mechanical or chemical modification of surface of teeth attached to denture base. However, the results have been mixed and conflicting. ${ }^{2}$

The most common tooth to debond is maxillary central incisor. The study conducted by Chung et $\mathrm{al}^{3}$ stated that sandblasting the surfaces of the teeth attached to denture base increased the bond strength as it causes mechanical roughness. The other authors Khandagale et al used chemical such as dichloromethane to do the same. ${ }^{4}$

Implant-supported overdentures have been used recently that resulted in enhancement of biting forces leading to increase in mechanical failure of the prosthesis. There is decrease in thickness of denture base materials in the anterior region because of use of bar and clip attachment that leads to failure as fracture of the denture base and debonding of the tooth from the base. Reinforcement of the mandibular implant-supported overdenture has been suggested to avoid this complication. ${ }^{5}$

\section{Materials and Methods}

Materials used in this study were

- Rolex wax (Rolex Modeling Wax No. 2, Ashoo Sons, Delhi)

- Polyvinyl Siloxane (3M ESPE AG, Seefeld Germany)

- Teeth (Acryrock, Ruthenium Dental Products Pvt. Ltd., Gujrat).

- Trevalon Heat Cure Polymethyl methacrylate resin (Dentsply India Pvt. Ltd., Delhi, India).

- Aluminum oxide grinding stone $9.5 \mathrm{~mm}$ (Dremel 952, Bengaluru, India).

- Dichloromethane $50 \mathrm{~mL}$ (Goyal Chemical Associates, New Delhi).

- Instron universal testing machine (IIT, Ropar, Punjab).

- The method used in this study was divided into the following steps:

Triangular Wax Blocks for Arranging Acrylic Resin Teeth A triangular wax block having each side $3.5 \mathrm{~cm}$ and length $4.5 \mathrm{~cm}$ with 60-degree angulation was fabricated using modeling wax (Rolex Modelling Wax No. 2, Ashoo Sons, Delhi, India) ( - Fig. 1) and checked using graph paper ( - Fig. 2). Its impression was made in polyvinyl siloxane putty material (3M ESPE AG, Seefeld, Germany) to standardize the size of wax blocks, and similar blocks were fabricated by pouring molten wax in the polyvinyl siloxane mold ( $\mathbf{- F i g .} \mathbf{3}$ ). The wax blocks were polished with soap solution, and tooth arrangement was done (-Fig. 4).

Preparation of Ridge Lap Surfaces of 100 Central Incisors One hundred cross-linked acrylic resin central incisors (Acryrock) of same mold were taken and divided into following five groups, 20 in each group.

Group A: Teeth were kept without any modification to the ridge lap surface (control group).

Group B: The glazed ridge lap surfaces of the acrylic teeth were treated with monomer, that is, methylmethacrylate using a camel brush 10 minutes before packing. A single application was done (-Fig. 5)

Group C: The surface glaze was removed by abrading the ridge lap surface with aluminum oxide grinding stone,

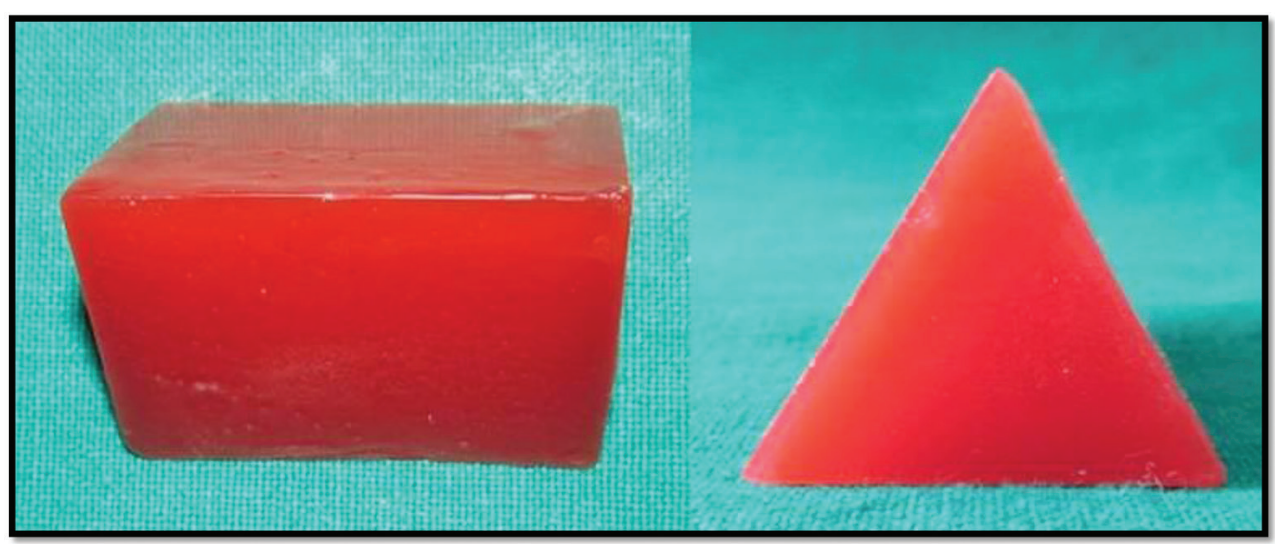

Fig. 1 Triangular wax blocks. 
Comparative Evaluation of Bond Strength Sharma et al.

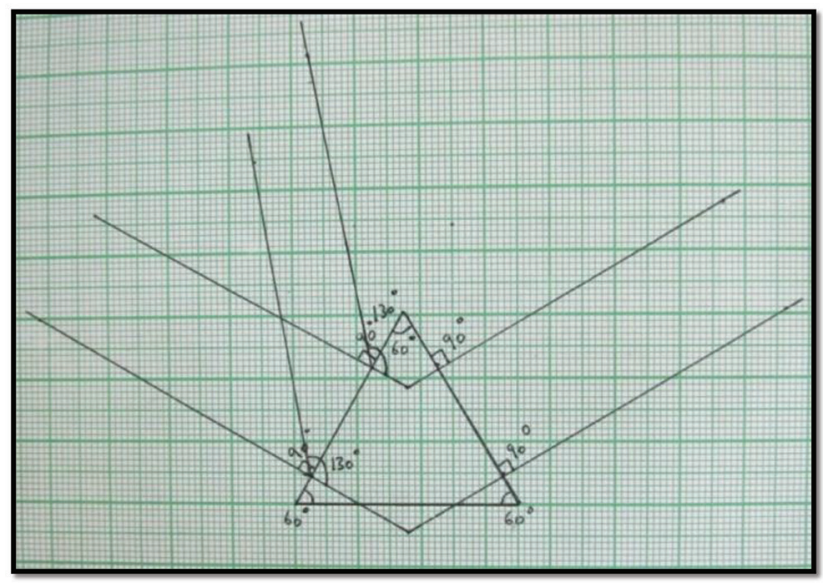

Fig. 2 Graph paper to check dimensions and angles.

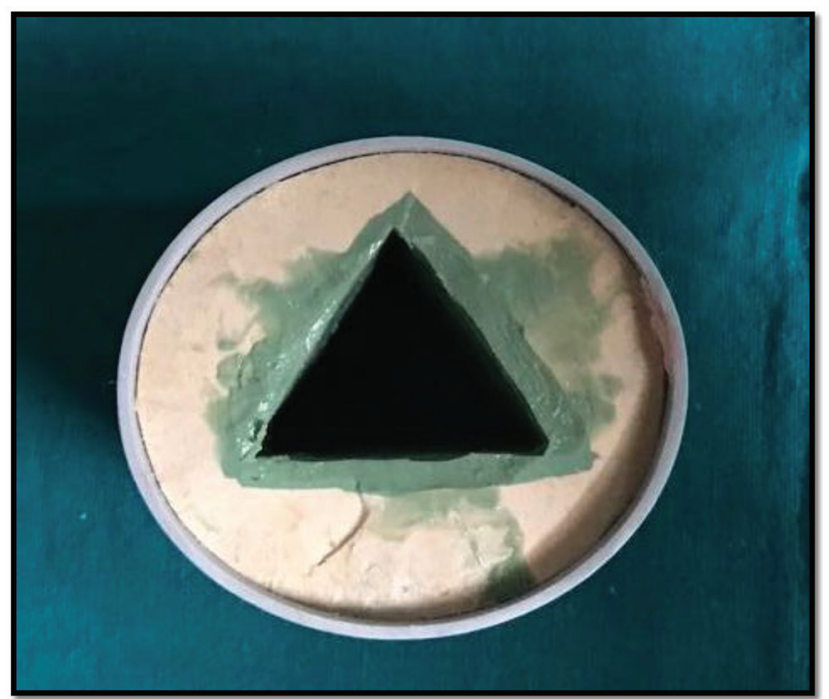

Fig. 3 Mold made from putty and light body.

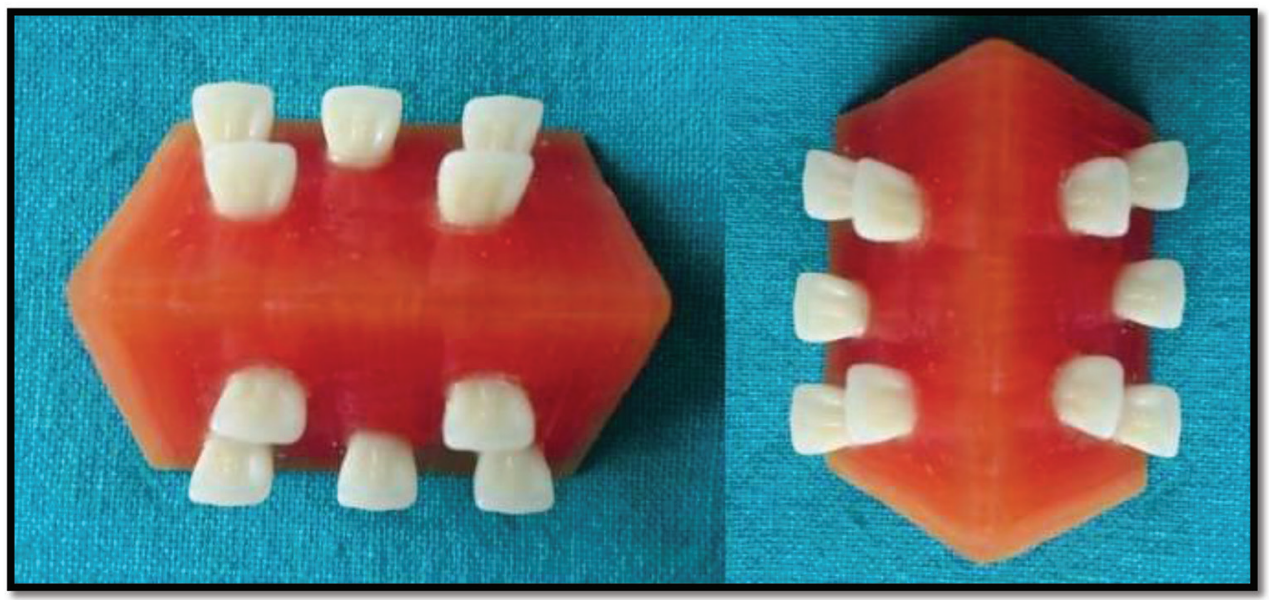

Fig. 4 Teeth arrangement on wax blocks.

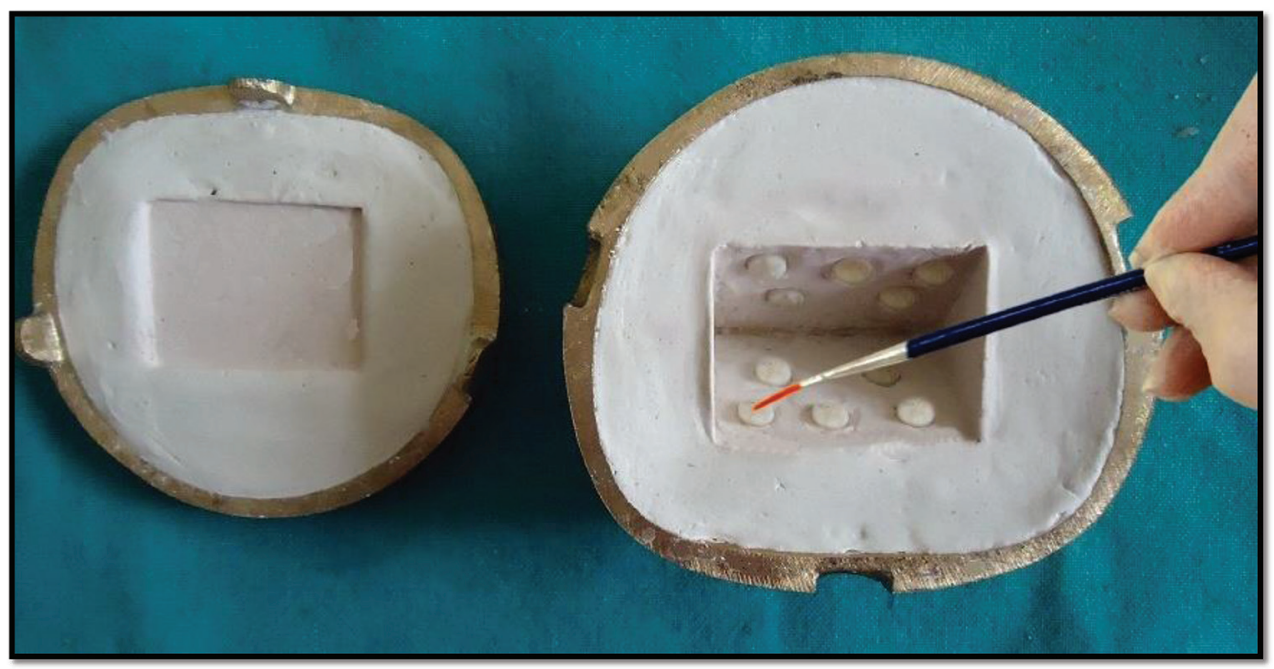

Fig. 5 Application of methylmethacrylate 
and then the teeth were treated with methyl methacrylate in the same manner as in group A ( - Fig. 6).

Group D: The glazed ridge lap surfaces of the acrylic teeth were treated with dichloromethane solvent with a camel

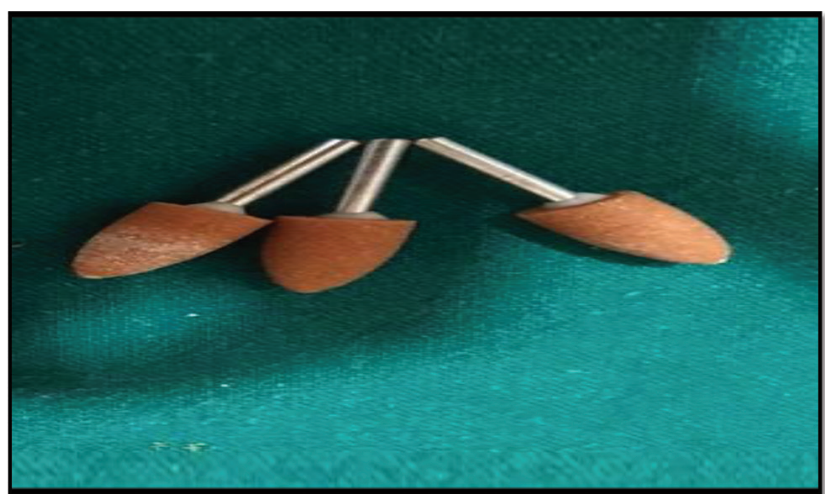

brush 10 minutes before packing. A single application was done (-Fig. 7).

Group E: The surface glaze was removed by abrading the ridge lap surface with aluminum oxide grinding stone, and then the teeth were treated with dichloromethane solvent in the same manner as group D.

\section{Arrangement of Teeth on Triangular Wax Blocks}

1. On a graph paper, an equilateral triangle of dimensions $3.5 \mathrm{~cm}$ was drawn, and lines were drawn on both sides of the triangle at an angle of 130 degrees. This was done to standardize the position and angulation of the teeth on the wax blocks.

2. Ten teeth were arranged on each block (five on each side), at an angle of 90 degrees so that on applying shear compressive force to the lingual surfaces of the teeth we could simulate the average angle of contact found in a class I occlusion between maxillary and mandibular anterior teeth, as reported by Khandagale et al. ${ }^{4}$

Fig. 6 Aluminum oxide grinding stone.

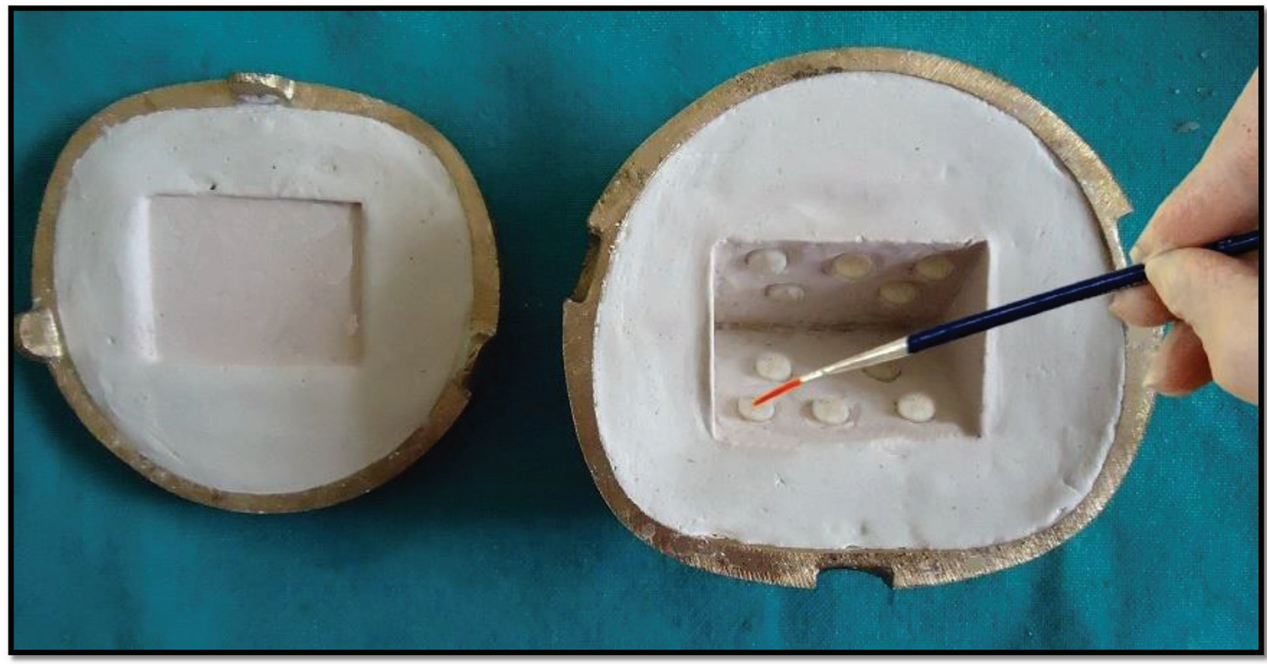

Fig. 7 Application of dichloromethane solvent.

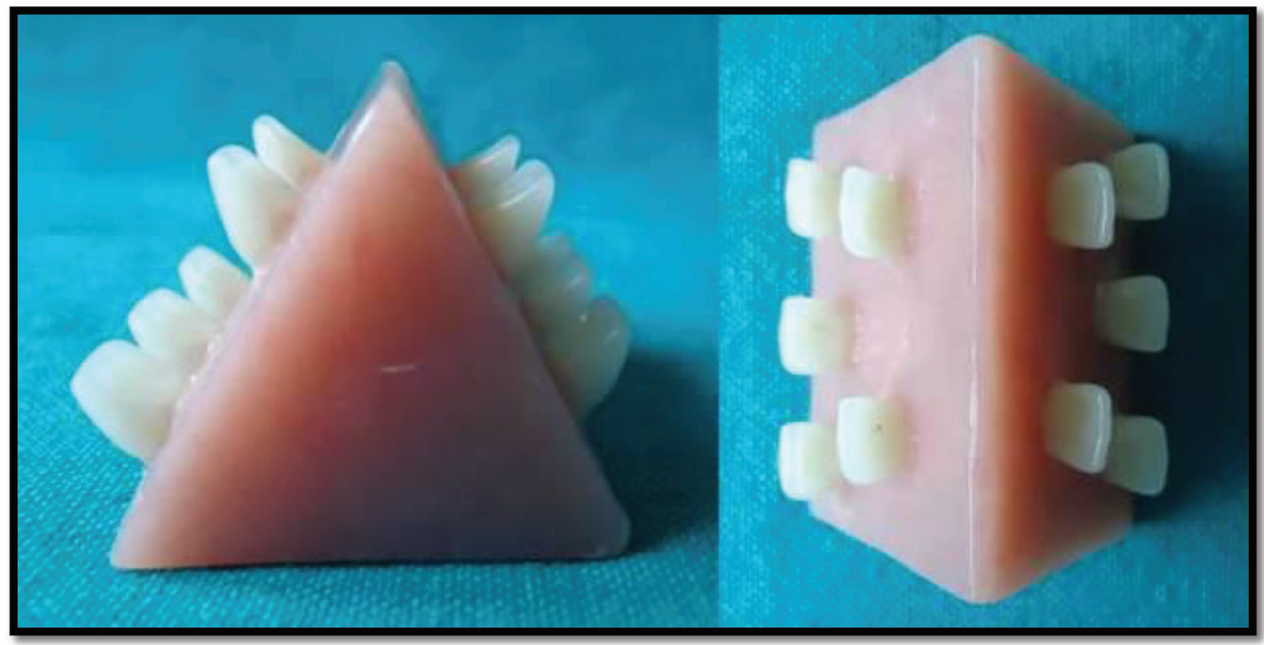

Fig. 8 Acrylized blocks with teeth arranged. 


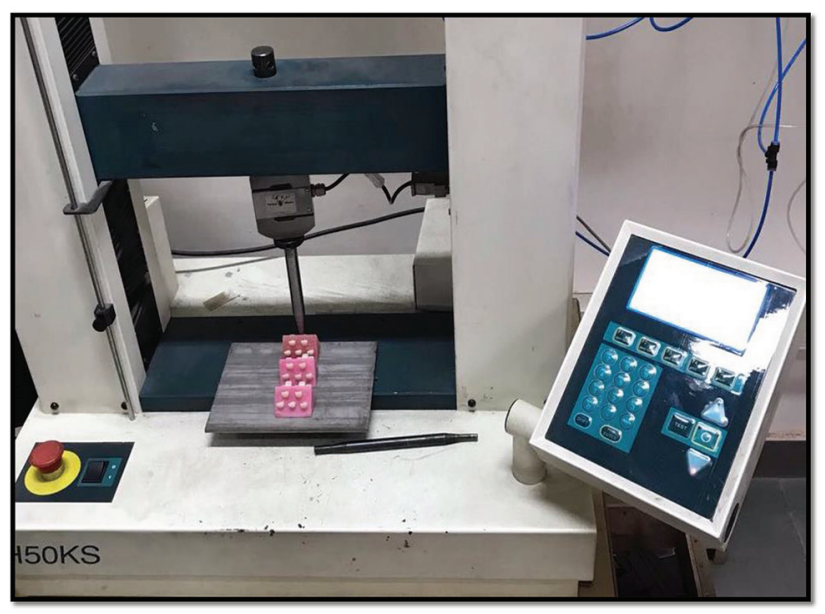

Fig. 9 Samples subjected to Instron universal testing machine.
3. Teeth of different groups were placed on different wax blocks.

\section{Processing of Wax Blocks}

Flasking, de-waxing, packing, and de-flasking were done according to manufacturer's instructions. Acrylic blocks with mounted teeth were then finished, rechecked on graph paper, and stored in water ( - Fig. 8 ).

\section{Measurement of Bond Strength}

The acrylic wax blocks were stabilized in a fixture so that no movement occurred during load application. Samples were subjected to Instron Universal Testing Machine ( - Fig. 9). Force was applied by a 3-mm-diameter stainless steel pin at crosshead speed of $5 \mathrm{~mm} / \mathrm{min}$ until detachment of teeth occurred and readings were recorded.

Table 1 Mean shear compressive load in different groups in kilo-newtons (KN)

\begin{tabular}{|l|l|l|l|l|l|}
\hline Specimen & Group A & Group B & Group C & Group D & Group E \\
\hline 1 & 0.910 & 1.146 & 1.990 & 1.240 & 2.050 \\
\hline 2 & 0.871 & 1.149 & 1.995 & 1.549 & 1.968 \\
\hline 3 & 1.055 & 1.474 & 1.999 & 1.695 & 1.902 \\
\hline 4 & 1.148 & 1.179 & 1.800 & 1.654 & 1.669 \\
\hline 5 & 1.048 & 1.539 & 1.827 & 1.512 & 1.678 \\
\hline 6 & 0.902 & 1.230 & 1.787 & 1.732 & 1.653 \\
\hline 7 & 0.910 & 1.475 & 1.933 & 1.249 & 1.773 \\
\hline 8 & 0.915 & 1.406 & 1.528 & 1.626 & 1.837 \\
\hline 9 & 0.966 & 1.295 & 1.525 & 1.349 & 1.871 \\
\hline 10 & 1.045 & 1.130 & 1.639 & 1.782 & 1.750 \\
\hline 11 & 0.981 & 1.377 & 1.589 & 1.616 & 2.166 \\
\hline 12 & 0.985 & 1.580 & 1.560 & 1.684 & 1.862 \\
\hline 13 & 0.979 & 1.339 & 1.870 & 1.787 & 1.802 \\
\hline 14 & 1.130 & 1.386 & 1.900 & 1.580 & 2.188 \\
\hline 15 & 1.146 & 1.540 & 1.538 & 1.528 & 2.030 \\
\hline 16 & 0.902 & 1.544 & 1.894 & 1.678 & 2.068 \\
\hline 17 & 0.915 & 1.349 & 1.976 & 1.475 & 2.049 \\
\hline 18 & 1.048 & 1.249 & 1.931 & 1.295 & 2.244 \\
\hline 19 & 0.981 & 1.528 & 2.025 & 1.525 & 1.933 \\
\hline 20 & 1.149 & 1.512 & 1.841 & 1.377 & 2.025 \\
\hline Average & 0.99 & 1.37 & 1.80 & 1.54 & 1.92 \\
\hline & & & & & \\
\hline
\end{tabular}

Table 2 Descriptive statistics of shear compressive load of all of the studied groups

\begin{tabular}{|l|l|l|l|l|}
\hline Groups & $N$ & Mean & Standard Error & $\begin{array}{l}\text { Standard } \\
\text { Deviation }\end{array}$ \\
\hline Group A & 20 & 0.99 & 0.092 & 0.020 \\
\hline Group B & 20 & 1.37 & 0.151 & 0.033 \\
\hline Group C & 20 & 1.80 & 0.177 & 0.039 \\
\hline Group D & 20 & 1.54 & 0.170 & 0.038 \\
\hline Group E & 20 & 1.92 & 0.175 & 0.039 \\
\hline
\end{tabular}

\section{Results}

The samples were subjected to shear compressive load under universal testing machine, and the results obtained are listed in - Table 1. The results were subjected to statistical analysis by applying analysis of variance and Bonferroni test for multiple group comparisons, and graphs were plotted.

The mean value of bond strength was highest for group $\mathrm{E}$ (modified by aluminum oxide abrasion prior to dichloromethane application), that is, 1.92, followed by group C (modified by aluminum oxide abrasion prior to monomer application), 


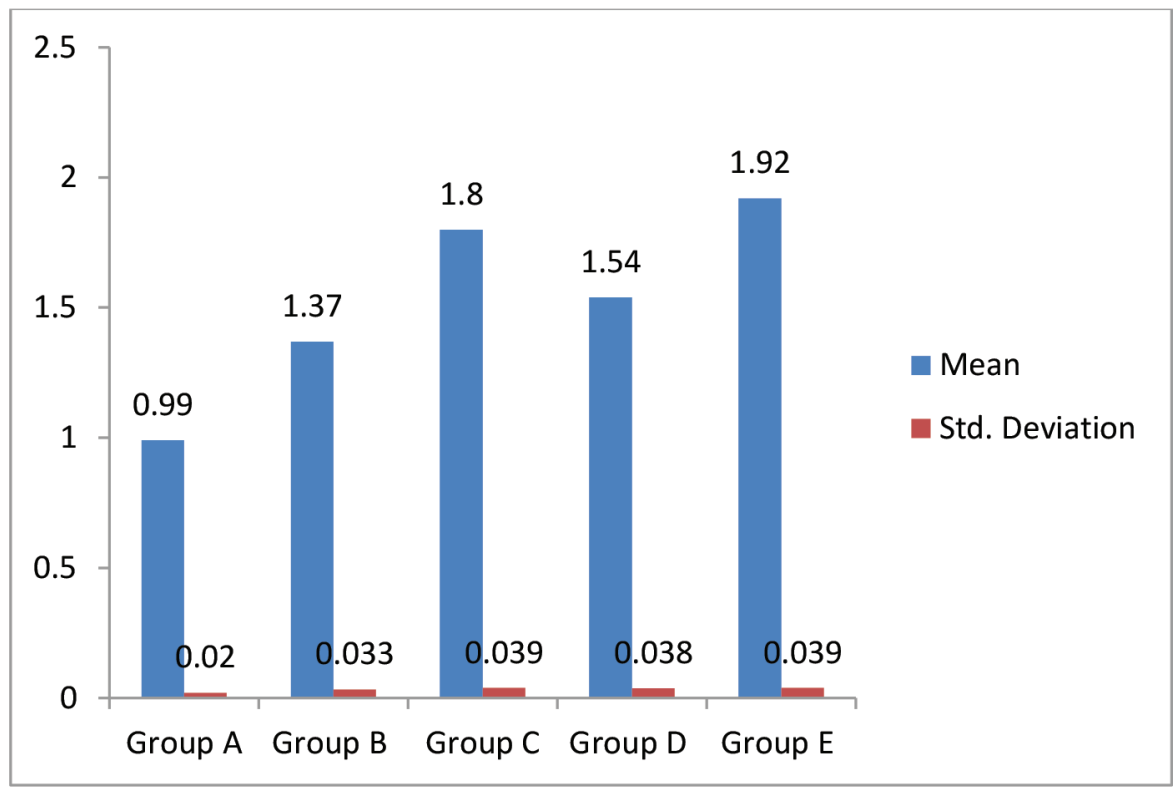

Fig. 10 Descriptive statistics of shear compressive load of all of the studied groups.

that is, 1.80 , group $\mathrm{D}$ (modified by dichloromethane application), that is, 1.54, group B (modified by monomer application), that is, 1.37, and lastly group A (control group), that is, 0.99 ( - Table 2 and $\boldsymbol{- \text { Fig. }}$ 10).

\section{Discussion}

Harold Vernon first introduced the use of methyl methacrylate in the form of a powder and liquid to be used as a denture base in the 1930s. It substituted vulcanized rubber (Vulcanite) patented by Goodyear ${ }^{6}$ in 1851. Dr. Walter Wright described the results of his clinical evaluation of methyl methacrylate resin. ${ }^{7.8}$ The acrylic resins represented such significant improvements for its application in denture base construction. By 1946 it was estimated that more than $95 \%$ of all dentures were constructed of methylmethacrylate polymers or copolymers with porcelain teeth. Since then the use of this material in denture construction has advanced by leaps and bound. Several rather significant improvements have been developed, which makes it more versatile. It has also become the most popular artificial material for denture teeth. The plastic teeth are of essentially the same composition as denture base resin, except for pigmentation to produce tooth shades of color. Apart from the advantage of economy, it bonds chemically to the denture base and gives a lifelike translucent quality, even in thin sections of less than $1 \mathrm{~mm} .{ }^{9}$ The teeth become an integral part of the prosthesis and the stiffness and strength of the entire denture increases. ${ }^{10}$

Studies that have evaluated the frequency of various denture repairs have found tooth debonding/fracture to be the most frequent in both complete and partial dentures followed by the midline fracture of complete dentures. ${ }^{11}$ The teeth that separate most often from the denture base are the maxillary incisors and canines. As resin denture teeth and denture base resins are slightly flexible, the resin tooth may dislodge from the denture base when the adhesion or mechanical retention between them fails. ${ }^{12}$ The lack of adequate bonding is believed to be the result of incompatible surface conditions at the tooth/base interface. This incompatibility is sodium alginate and the difference in the structure of the two components due to their different processing. ${ }^{13}$

The group in which monomer application was done prior to packing (i.e., group B) showed higher bond strength value as compared with the control group. The increase in bond strength on monomer application was also reported by Rubina et al, ${ }^{2}$ Jain et al, ${ }^{1}$ Madhav et al,,${ }^{14}$ Patil et al,,${ }^{15}$ and Saavedra et al. ${ }^{16}$

Group $\mathrm{C}$ in which removal of the surface glaze was done prior to monomer application showed bond strength better than the control group and monomer application. Grinding the ridge lap surface with an aluminum oxide abrasive stone was seen to significantly increase the bond strength between acrylic teeth and denture base resin, as reported by Bragaglia et al. ${ }^{17}$

Group D showed the second highest bond strength, that is, dichloromethane solvent application before packing. This result is in consonance with the findings of Takahashi et $\mathrm{al}_{1}{ }^{18}$ Chai et $\mathrm{al},{ }^{19}$ and Kaura et $\mathrm{al} .{ }^{20}$ Dichloromethane is a non-polymerizable solvent. It facilitates the "swelling "of denture tooth polymer and increases mixing of material. The strength of material depends on mixing of polymer fibers into liquid. Therefore, dichloromethane improves bond between teeth and denture base for this treatment. SEM study revealed that there is formation of pores and channels of approximately $1 \mu \mathrm{m}$ in diameter on the treated surface if the teeth with dichloromethane, and these channels interconnect frequently as reported by Khandagale et al. These features probably represent spaces previously occupied by resin polymer that was dissolved. Such a surface topography may suggest micromechanical retention as another mechanism to explain the advantage of dichloromethane in improving bonding. 
Chai et a ${ }^{18}$ demonstrated that dichloromethane improved the bond strength about three times more than untreated teeth.

Group E showed the highest bond strength, that is, removal of surface glaze by aluminum oxide stone followed by application of dichloromethane before packing. Ridge lap surface roughening by aluminum oxide abrasive stone increased the bond strength because the roughened surface provided a wider contact area with denture base resin and greater micromechanical retention. SEM analysis showed that the surface treatment with abrasive stone resulted in higher surface roughness compared with no treatment or monomer etching, as reported by Bragaglia et al. ${ }^{17}$

This study is the first of its kind in which both the chemical and mechanical modifications were made on the ridge lap surface of 100 cross-linked acrylic teeth. According to Takahashi et al, when data from experiment were separated according to the denture teeth type, the bond strength of conventional resin teeth surpassed that of the cross-linked teeth. This phenomenon was explained by the presence of a lesser amount of unlinked polymer chain in the cross-linked teeth compared with conventional resin teeth. Therefore, less unlinked polymer chains are available in the cross-linked teeth for the development of an interwoven polymer between the teeth and denture base.

Modification of the ridge lap surface of the maxillary anterior teeth by application of solvents (like monomer and dichloromethane) or mechanical modification (by aluminum oxide grinding stone) followed by chemical modification is hence recommended to enhance their bond strength to the denture bases. Dichloromethane application after abrasion of the ridge lap surface with aluminum oxide grinding stone provides the highest bond strength values without any expensive material or extra time.

\section{Conclusion}

Within the limitations of this study, it was found that the modifications of the ridge lap surface improved the bond strength as compared with the unmodified surface. These modifications were simple and practicable. Maximum bond strength was obtained with grinding the ridge lap surface with aluminum oxide and then applying dichloromethane, followed by the same mechanical modification as mentioned above and then applying monomer, dichloromethane application, monomer application, and control group, respectively, in descending order.

Hence, removal of surface glaze of ridge lap surface of acrylic resin teeth followed by application of dichloromethane is highly recommended because the results show a highly significant bond strength as it may prevent future detachment of the teeth from the removable prosthesis.

Application of monomer, dichloromethane, removal of surface glaze by aluminum oxide grinding stone-all these methods have shown to increase the bond strength. Hence, all the aforementioned methods can be used especially in case of the maxillary anterior teeth, which commonly dislodge during routine use of complete denture prosthesis.

\section{Funding}

None.

\section{Conflict of Interest}

None declared.

\section{References}

1 Jain G, Palekar U, Awinashe V, Mishra SK, Kawadkar A, Rahangdale T. The effect of different chemical surface treatments of denture teeth on shear bond strength: a comparative study. J Clin Diagn Res 2014;8(6):ZC15-ZC18

2 Rubina KM, Singh M. Evaluation of bond strength between modified ridge lap surface of acrylic teeth and PMMA denture base resin-an in vitro study. Indian J Dent Sci 2015;2:41-44

3 Chung $\mathrm{KH}$, Chung CY, Chung CY, Chan DCN. Effect of pre-processing surface treatments of acrylic teeth on bonding to the denture base. J Oral Rehabil 2008;35(4):268-275

4 Khandagale TS, Sanyal PK, Tewary S. Comparative evaluation of bond strength of surface treated and surface modified anterior acrylic teeth to heat cure denture base: an in vitro study. Int J Oral Care Res 2017;5(2):1-8

5 Rodrigues AH. Metal reinforcement for implant-supported mandibular overdentures. J Prosthet Dent 2000;83(5):511-513

6 Kelly EB. Has the advent of plastics in dentistry proved of great scientific value? J Prosthet Dent 1951;1(1-2):168-176

7 Uzun G, Hersek N, Tinçer T. Effect of five woven fiber reinforcements on the impact and transverse strength of a denture base resin. J Prosthet Dent 1999;81(5): 616-620

8 Alla RK, Sajjan S, Alluri VR, et al. Influence of fiber reinforcement on the properties of denture base resins. J Biomater Nanobiotechnol 2013;4, 91-97 (Page 91 in history)

9 Thean HPY, Chew CL, Goh KI. Shear bond strength of denture teeth to base: a comparative study. Quintessence Int 1996;27(6):425-428

10 Büyükyilmaz S, Ruyter IE. The effects of polymerization temperature on the acrylic resin denture base-tooth bond. Int J Prosthodont 1997;10(1):49-54

11 Darbar UR, Huggett R, Harrison A. Denture fracture-a survey. Br Dent J 1994;176(9):342-345

12 Zuckerman GR. A reliable method for securing anterior denture teeth in denture bases. J Prosthet Dent 2003;89(6):603-607

13 Cunningham JL, Benington IC. A new technique for determining the denture tooth bond. J Oral Rehabil 1996;23(3):202-209

14 Madhav GV, Raj S, Yadav N, Mudgal I, Mehta N, Tatwadiya R. Shear bond strength of acrylic teeth to acrylic denture base after different surface conditioning methods. J Contemp Dent Pract 2013;14(5):892-897

15 Patil SB, Naveen BH, Patil NP. Bonding acrylic teeth to acrylic resin denture bases: a review. Gerodontology 2006;23(3):131-139

16 Saavedra G, Valandro LF, Leite FPP, et al. Bond strength of acrylic teeth to denture base resin after various surface conditioning methods before and after thermocycling. Int J Prosthodont 2007;20(2):199-201

17 Bragaglia LE, Prates LHM, Calvo MCM. The role of surface treatments on the bond between acrylic denture base and teeth. Braz Dent J 2009;20(2):156-161

18 Takahashi Y, Chai J, Takahashi T, Habu T. Bond strength of denture teeth to denture base resins. Int J Prosthodont 2000;13(1):59-65

19 Chai J, Takahashi Y, Takahashi T, Habu T. Bonding durability of conventional resinous denture teeth and highly crosslinked denture teeth to a pour-type denture base resin. Int J Prosthodont 2000;13(2):112-116

20 Kaura A, Shah R, Lalit J. An in vitro study of bond strength of bond strength between acrylic resin teeth and denture base resin. BUJOD 2014;4:38-43 